\title{
Cause Traced to Maintenance
}

National Cancer Institute

\section{Source}

National Cancer Institute. Cause Traced to Maintenance. NCI Thesaurus. Code C91880.

Problems traced to improper routine or preventative maintenance. 